Article

\title{
Technological Bias and Its Influencing Factors in Sustainable Development of China's Transportation
}

\author{
Shuai Zhang ${ }^{1, *}$, Xiaoman Zhao ${ }^{2}$, Changwei Yuan ${ }^{3}$ and Xiu Wang ${ }^{4}$ \\ School of Economics, Nankai University, Tianjin 300071, China \\ Department of Economics, Xi'an Jiaotong University City College, Xi'an 710018, China; zxm_becca@163.com \\ College of Transportation Engineering, Chang'an University, Xi'an 710064, China; yuanchangwei@126.com \\ 4 Institute of Mechanics, Jinzhong University, Jinzhong 030619, China; wangx@jzxy.edu.cn \\ * Correspondence: 1120180908@mail.nankai.edu.cn
}

Received: 20 June 2020; Accepted: 12 July 2020; Published: 15 July 2020

check for updates

\begin{abstract}
The bias of technological progress, particularly relating to energy saving and carbon emissions reduction, plays a significant role in the sustainable development of transportation, and has not yet received sufficient attention. The objectives of this paper were to examine the bias of technological change (BTC), input-biased technological change (IBTC), and output-biased technological change (OBTC), and their influencing factors in the sustainable development of China's regional transportation industry from 2005 to 2017. A slack-based measure (SBM) Malmquist productivity index was adopted to measure the BTC, IBTC, and OBTC by decomposing green total factor productivity. The results revealed that: (1) Continuous technological bias progress and input-biased technological progress existed in China's transportation development from 2005 to 2017, making an important contribution to green total factor productivity. The output-biased technological change was close to 1 , indicating a slight impact on the sustainable development of the transportation industry; (2) The bias of technological progress in eastern regions was slightly greater than that in central regions, and obviously greater than that in western regions. Moreover, different provinces experienced different types of technological bias change, with four major types observed during the research period; (3) The input-biased technology of a majority of provinces tended to invest more capital relative to labor, using more capital comparing to energy, and consume more energy relative to labor, while the output-biased technology of most provinces tended to produce desirable outputs (value added in transportation) and reduce the byproduct of $\mathrm{CO}_{2}$ relatively; (4) Average years of education, green patents in transportation, industrial scale, and local government fiscal expenditure in transportation significantly contributed to promoting the bias of technological progress, which was inhibited by the R\&D investment. This study provides further insight into the improvement of sustainable development for China's transportation, thereby helping to guide the government to promote green-biased technological progress and optimize the allocation of resources.
\end{abstract}

Keywords: technological bias; sustainable development; transportation; China

\section{Introduction}

As a basic sector of the economy, the transportation industry plays an active role in current society [1], and is associated with regional economic development, quality of people's lives, and social welfare [2,3]. However, due to fossil fuel consumption and exhaust emissions of vehicles such as cars and aircraft, this sector has become a significant contributor to overall carbon emissions, accounting for approximately one quarter of total energy-related $\mathrm{CO}_{2}$ emissions globally [4]. The International Energy Agency (IEA) predicts that the proportion of global energy consumption accounted for by transportation will increase to $53 \%$ and $80 \%$ in 2030 and 2050, respectively [5], indicating that $\mathrm{CO}_{2}$ 
emissions will also continually increase for the foreseeable future. China's transportation sector accounts for almost $20 \%$ of its national energy consumption [6], while the volume of transportation energy use has continued to increase [7]. Due to the high energy intensity of this sector, transportation is the second-largest contributor to national carbon emissions, accounting for 18.9\% [8]. The issue of carbon emission reduction in transportation has thus received extensive attention amongst policy-makers and scholars [9-11]. However, given the importance of this sector to the economy, it is worth noting that more attention should be paid to the overall sustainable development of the transportation industry, rather than focusing only on the reduction of $\mathrm{CO}_{2}$ emissions.

Technological progress is the undoubted critical driver of sustainable development, and is regarded as a long-term approach to achieve the coordinated development of economy and environment. According to the neoclassical economic growth theory, technological change is exogenous and neutral. However, many studies have revealed that technological changes are biased in many cases [12-14]. The bias of technological progress refers to changes in the marginal rate of substitution (MRS) of inputs or outputs, promoting the marginal production of elements, and then realizing the optimal allocation of scarce resources. While technological progress in economic growth tends to use fewer resources and produce fewer pollutants, it is possible to achieve the dual goals of energy saving/emissions reduction and effective promotion of economic growth. Thus, it is necessary to explore technological bias and its influencing factors in the sustainable development of China's transportation industry.

In fact, there exist numerous studies dedicated to promoting the sustainable development of transportation. The majority of studies focused on the evaluation of transportation sustainability [15-19] and the transport policies or pathways to achieve sustainable development in transportation [20-23]. With respect to the technology of transportation sustainability, many studies were devoted to investigating alternative energy technology and vehicle technology [24-26]. At the same time, based on the decomposition of the green total productivity index, an increasing amount of research has examined technological progress in the transportation industry [27-29]. However, we noted that these studies only investigated overall technological change and its contribution to green TFP by decomposing total factor productivity into efficiency change (EC) and technological change (TC), ignoring the bias of technological change or the substitution effect between input/output elements.

If we only focus on the energy depletion issue, we can find that several studies have been devoted to exploring technological bias between energy and other input elements. Lin and Ahmad [2] and Lin and Raza [30] employed a trans-log approach, using energy, capital, labor, and conversion turnover as output indicators to analyze the substitution effect between energy, capital, and labor in Pakistan's transportation industry. The same method was used by Lin and Xie [31] to analyze China's transportation industry. However, not only does the conception of transportation sustainability imply saving resources but also implies effective governance of environmental issues. Thus, on the one hand, the existing literature ignored the technological bias of sustainable development, in particular, the technological bias between desirable and undesirable outputs. On the other hand, the influencing factors of technological bias are also an important and valued topic that has been rarely seen in previous studies, which can provide an effective way to promote innovation of technological bias in the field of transportation and then improve the sustainable development of transportation. Besides, the method used in Lin and Ahmad [2], Lin and Raza [30], and Lin and Xie [31] required parameters and models to be set in advance, which may lead to inaccuracy of the estimation results.

When compared with previous studies, the contributions of this paper can be summarized as follows. Firstly, by incorporating slack-based measure (SBM) and Malmquist productivity index (MPI), we developed a decomposition form to evaluate the bias of technological change of transportation sustainability, which can avoid the drawback of the trans-log approach and was not applied in previous studies in this topic. Secondly, based on the proposed approach, we evaluated the sustainability performance, decomposed the input- and output-biased technological change, and then identified the direction of technological bias between elements for China's regional transportation industry during 2005-2017. Differently from the works of Lin and Ahmad [2], and Lin and Raza [30], and Lin and 
Xie [31], this paper focused on the input-biased and output-biased technological change of sustainable development in transportation simultaneously instead of the input-biased technology only, which has not been valued in previous studies. In other words, the technological bias between energy and other input elements as well as that between desirable and undesirable output were both explored, which was more consistent with the concept of sustainable development of transportation compared with previous literature. Thirdly, different from the existing studies, we furthermore explored the factors of influencing technological bias. The identification of technological bias and its influences can provide transportation managers with a powerful tool to identify the problems faced in achieving sustainable development, so that more effective policies can be formulated to promote carbon emission reduction and the effective development of transportation.

The remainder of this paper is organized as follows. Section 2 provides a brief review of the previous literature. Section 3 presents the SBM Malmquist productivity index with undesirable outputs. This section also outlines the approach used to decompose and identify technological bias, introduces the concept of the direction of technological bias, and illustrates the data and sources used in this paper. In Section 4, we show our analysis of the results relating to China's transportation industry during the period of 2005 to 2017. Finally, some conclusions are provided in Section 5.

\section{Literature Review}

\subsection{Related Research on the Bias of Technological Change}

Technological bias plays an important role in total factor productivity growth and economic development, which have been one of the popular research topics in recent decades. A large number of scholars have investigated technological bias from an empirical perspective in various areas; for instance, Zhu et al. [32] utilized a third-order trans-log cost function to examine technological bias in China's wheat sector, and found that this sector experienced labor- and fertilizer-saving and machinery-using technological bias during the period of 1991-2010. Dewitte et al. [33] proposed a nonparametric approach to measure technological bias under endogeneity and discussed technological bias in Belgian manufacturing firms. Yang et al. [34] employed a stochastic frontier approach (SFA) to examine technological bias and substitution elasticity for R\&D activity in China's manufacturing industry.

However, none of these studies incorporated energy or environmental elements. Recently, an increasing number of researchers have incorporated energy or pollutant outputs into analyses of technological bias [12-14,34,35]; for instance, Chen and Yu [12] discussed the bias of technological change in 99 countries and revealed that these countries showed capital-using/labor-saving, capital-using/energy-saving, and energy-using/labor-saving technological bias in 1991-2003. Li et al. [35] found that industries in most regions of China have a tendency to use water and to reduce water-polluting emissions.

Previous studies have adopted a range of approaches to measure technological bias, which fall into three main types as follows: (1) normalized supply-side system approach, (2) stochastic frontier approach (SFA), and (3) data envelopment analysis (DEA). Each method has its advantages and disadvantages; thus, the choice of method is dependent on the specific situation. Although the former two methods have been widely applied, each has strict assumptions. The first is generally based on the constant elasticity of substitution (CES) production function, which requires the unrealistic assumption that factor substitution elasticity remains unchanged. Some parameters and the form of the production model must be set in advance for the SFA, which can lead to inaccurate results. In contrast, DEA avoids these issues and, in addition, is also suitable for the situation of multi-input and multi-output product processes. The normalized supply-side system and SFA are only suitable for a single-output production system, ignoring the measure of output-biased technology. As a result, the DEA approach is currently a popular method in the literature to measure the bias of technological change. 


\subsection{Related Research on Transportation Sustainability Measurement}

In recent decades, environmental issues have attracted many researchers to evaluate sustainable development in the transportation sector. For instance, Reisi et al. [36] developed a composite transport sustainability index by the method of principal component analysis (PCA) and evaluated the sustainable development performance of urban transport in Melbourne. Persia et al. [37] examined the sustainability of the urban transport system in 50 Italian cities. Rajak et al. [16] incorporated a fuzzy logic approach to measuring the sustainable transportation system performance. Shiau et al. [17] explored Taiwan's transport sustainability by a two-stage principal component analysis (TSPCA) method based on 26 key indexes during 1993 and 2010. Gruyter et al. [38] measure the performance of public transport sustainability for the 19 Asian cities.

It is worth noting that the studies mentioned above were based on the indicator system evaluation and need to determine the weight in advance. In recent years, an increasing number of pieces of literature contributed to measuring the sustainability performance of transportation by the DEA, which can avoid the subjectivity of index weight determination. For instance, Zhou et al. [39] used output-oriented DEA to measure the carbon emission performance of China's transportation industry. Liu et al. [40] and Bi et al. [41], by adopting non-radial DEA, analyzed the environmental efficiency of transportation and road/railway transport, respectively. Using super efficiency, Wei et al. [18] evaluated the sustainability efficiency of urban transport in 34 Chinese cities. However, these approaches are traditional DEA approaches. Since the slack-based measure is widely applied in the measure of efficiency with undesirable outputs, an increasing number of scholars have used SBM and its modifications to evaluate environmental efficiency in transportation. For example, using non-radial SBM-DEA, Chang et al. [42] and Park et al. [43] analyzed environmental efficiency and carbon emission efficiency. Incorporating super efficiency, Song et al. [44] and Tian et al. [45] evaluated sustainability performance for road transport and transportation, respectively. In addition, several studies noted that the transportation system is a network system with a complex internal structure, and thus used network DEA in their researches [46,47].

In addition, few studies have been devoted to exploring green TFP, particularly in relation to the transportation industry in China. The DEA-based Malmquist index is a popular tool used to measure green TFP in these studies. For instance, based on a bootstrapped non-radial Malmquist index, Zhang et al. [19] defined a special Malmquist index to investigate the dynamic changes of the total factor $\mathrm{CO}_{2}$ emission performance in China's regional transportation from 2002 to 2010. At the same time, Liu et al. [48] constructed a similar index to examine the total factor carbon emission performance of 12 China's airlines using a global MPI. Huang et al. [28] employed a global MPI to evaluate the sustainability total factor productivity of 15 international airline companies. Using the Malmquist Luenberger index, Li et al. [8] and Yu et al. [49] evaluated green total productivity in China's transportation industry. In addition, Liu et al. [29] applied the Hicks Moorsteen index to analyze the change and regional differences of environmental productivity in China's road transport sector from 2005 to 2014, while Lee et al. [50] made comparisons among green TFP in 34 international airlines using the Luenberger index. By incorporating the Luenberger and Hicks Moorsteen indexes, Seufert et al. [51] developed a new index, referred to as the "by-production Luenberger Hicks Moorsteen indicator", to measure green TFP.

\subsection{Related Research on the Technology of Transportation Sustainability}

Technology, especially green technology, has an important influence on transportation sustainability. On the one hand, alternative energy technology and vehicle technology are widely regarded as one of the important approaches to achieve sustainable developments of transportation. Thus, most of the studies discussed the effect of those technologies on the environment and simulated carbon emissions under different technology scenarios. For instance, Onat et al. [24] assessed the impact of vehicle technology on the economy, environment, and society based on the life cycle assessment (LCA) approach. Using multi-criteria decision making (MCDM) method, Streimikiene et al. [25] 
compared the effect of transport technology on the environment from the perspective of cleaner vehicle fuels and cleaner vehicle technologies. Tsita and Pilavachi [26] used long-range energy alternatives planning (LEAP) to predict the $\mathrm{CO}_{2}$ emissions from 2010 to 2050 under different scenarios that are based on alternative technologies. Tang et al. [20] simulated and analyzed the carbon emission reduction potential of China's intercity passenger transport under different technologies.

On the other hand, under the analysis framework of green productivity, most of the scholars investigated the technological change by decomposing the green productivity index based on the DEA-Malmquist productivity index $[8,19,48,50]$. In addition, considering the differences between regions, Yu et al. [49] also analyzed the technology gap change (TGC) from the perspective of the metal frontier. Huang et al. [28] also discussed the technological scale change (STCH) in their work. Using the Hicks-Moorsteen index, Liu et al. [29] constructed a new decomposition form to investigate technological progress in China's road transport from 2005 to 2014. Mavi et al. [52] explored the eco-innovation for Iran's freight transportation over the period of 2014-2017. In addition, by incorporating the logarithmic mean Divisia index method (LMDI) and production theoretical decomposition analysis (PDA), Feng et al. [27] examined the effect of production technology and energy-saving technology on the $\mathrm{CO}_{2}$ emission for China's transportation industry during 2004 and 2016. However, they all ignored the technological bias in the transportation industry.

To the best of our knowledge, only a few studies have explored the technological bias between energy and other elements. By combining the energy into production progress, Lin and Ahmad [2] and Lin and Raza [30] employed a trans-log production function approach to analyze the substitution between input factors in Pakistan's transportation industry. Lin and Xie [31], using the same approach, revealed a high elasticity of substitution between energy and labor, and capital and energy, for China's transportation.

From the review of the previous literature noted above, we note that the technological bias has not received enough attention in transportation, especially in China. However, the bias of technological progress, especially the technologies of energy saving and carbon emission reduction, can improve the utilization efficiency of scarce resources such as energy, reduce pollution outs, promote the improvement of environmental efficiency, and is the major driver of achieving sustainable development of the transportation industry. In addition, although the recent three studies have explored the technological bias in transportation, they only focused on the technological bias of input elements, ignoring the output-biased technological change under the framework of sustainable development and, in particular, the technological bias between desirable outputs and $\mathrm{CO}_{2}$. Additionally, the strict assumption of a trans-log production function may have led to inaccurate results, as discussed above.

In the present paper, we thus incorporated a slack-based measure with undesirable outputs and the Malmquist productivity index to measure and identify technological bias and its directions, in order to derive more robust results. Furthermore, we investigated the influences on technological bias in the transportation industry. The results can be used to guide the promotion of technology innovation, improve technological progress, and support sustainable development in transportation.

\section{Methods and Data}

To measure the bias of technological change, Färe et al. [53] developed a decomposition method that decomposes the MPI into a magnitude index, an input bias index, and an output bias index. However, this approach is not suitable for a situation that includes undesirable byproducts. One alternative approach is the use of the directional distance function (DDF), which has been applied in previous studies to define the green productivity change, and is often subjectively defined as $\left(-g_{x}, g_{y},-g_{b}\right)$. However, the results are highly sensitive to the choice of DDF [54], i.e., different DDFs can lead to different conclusions. The slack-based measure with an undesirable output proposed by Tone et al. [55] also can be used to measure the environmental efficiency and can avoid the choice of DDF, which has been applied in many studies $[56,57]$. Thus, in this paper, we incorporated this approach and the MPI, presenting 
an SBM Malmquist productivity index. We then decomposed and measured the technological bias for China's transportation industry.

\subsection{Slack-Based Measure (SBM) with Undesirable Output}

We assume that there are $N$ decision-making units (DMUs) each having $M$ inputs, $S$ desirable outputs, and $I$ undesirable outputs, as represented by $x \in R_{M^{\prime}}^{+} y \in R_{S}^{+}$, and $b \in R_{I}^{+}$, respectively. We also suppose that $X, Y$, and $B$ are defined as: $X=\left[x_{1}, x_{2}, \cdots, x_{n}\right] \in R^{M \times N} ; Y=\left[y_{1}, y_{2}, \cdots, y_{n}\right] \in R^{S \times N}$, and $B=\left[b_{1}, b_{2}, \cdots, b_{n}\right] \in R^{I \times N}$, respectively. We then define the DEA production possibility set, $P(x)$, as

$$
P(x)=\{(x, y, b) \mid: x \geq X \lambda, Y \leq Y \lambda, B \geq B \lambda, \lambda \geq 0\}
$$

Based on $P(x)$, according to Tone [48], the SBM with undesirable outputs is defined as

$$
\begin{gathered}
\rho_{k}=\min \frac{1-\frac{1}{M} \sum_{m=1}^{M} \frac{s_{m}^{x-}}{x_{m k}}}{1+\frac{1}{M+1}\left(\sum_{s=1}^{S} \frac{s_{s}^{y+}}{y_{s k}}+\sum_{i=1}^{I} \frac{s_{i}^{b-}}{b_{i k}}\right)} \\
\text { s.t. X } \lambda+s^{x-}=x_{k^{\prime}} Y \lambda-s^{y+}=y_{k^{\prime}} B \lambda+s^{b-}=b_{k^{\prime}} \lambda \geq 0, s^{x-}, s^{y+}, s^{b-} \geq 0
\end{gathered}
$$

where $s^{x-}, s^{y+}$, and $s^{b-}$ denote the slack value of inputs, desirable outputs, and undesirable outputs, respectively. $x_{m k^{\prime}} y_{s k^{\prime}}$ and $b_{i k}$ denote the $m$ th input, sth desirable output, and ith undesirable output of the $k$ th DMU, respectively. $\rho_{k}$ is the environmental efficiency of the $k$ th DMU, with a value between $[0,1]$. A $\rho_{k}$ value less than unity indicates that DMU $k$ is inefficient.

\subsection{Green Malmquist Productivity Index}

Assume that $\rho_{k}^{t}\left(x^{t+1}, y^{t+1}, b^{t+1}\right)$ and $\rho_{k}^{t+1}\left(x^{t+1}, y^{t+1}, b^{t+1}\right)$ are the efficiency values of the $k$ th DMU based on period $t+1$ inputs, desirable and undesirable outputs under the periods $t$ and $t+1$ production technology, respectively, while $\rho_{k}^{t}\left(x^{t}, y^{t}, b^{t}\right)$ and $\rho_{k}^{t+1}\left(x^{t}, y^{t}, b^{t}\right)$ are the efficiency scores based on period $t$ inputs, desirable and undesirable outputs under the period $t+1$ production technology. Based on the DEA production possibility set and model (2), following Fare et al. [58], we defined the green Malmquist productivity index of China's transportation as

$$
M P I_{k}^{t, t+1}=\left[\frac{\rho_{k}^{t}\left(x^{t+1}, y^{t+1}, b^{t+1}\right)}{\rho_{k}^{t}\left(x^{t}, y^{t}, b^{t}\right)} \times \frac{\rho_{k}^{t+1}\left(x^{t+1}, y^{t+1}, b^{t+1}\right)}{\rho_{k}^{t+1}\left(x^{t}, y^{t}, b^{t}\right)}\right]^{1 / 2}
$$

where $\mathrm{MPI}_{k}^{t, t+1}>1\left(\mathrm{MPI}_{k}^{t, t+1}<1\right)$ indicates that green TFP increased (regressed) from period $t$ to $t+1$ for DMU $k$. We can then decompose the MPI into efficiency change and technological change as

$$
M P I_{k}^{t, t+1}=E C_{k}^{t, t+1} \times T C_{k}^{t, t+1}=\frac{\rho_{k}^{t+1}\left(x^{t+1}, y^{t+1}, b^{t+1}\right)}{\rho_{k}^{t}\left(x^{t}, y^{t}, b^{t}\right)} \times\left[\frac{\rho_{k}^{t}\left(x^{t}, y^{t}, b^{t}\right)}{\rho_{k}^{t+1}\left(x^{t}, y^{t}, b^{t}\right)} \times \frac{\rho_{k}^{t}\left(x^{t+1}, y^{t+1}, b^{t+1}\right)}{\rho_{k}^{t+1}\left(x^{t+1}, y^{t+1}, b^{t+1}\right)}\right]^{1 / 2}
$$

where the first term, $\rho_{k}^{t+1}\left(x^{t+1}, y^{t+1}, b^{t+1}\right) / \rho_{k}^{t}\left(x^{t}, y^{t}, b^{t}\right)$, denotes the change of relative efficiency for the $k$ th DMU from period $t$ to $t+1$, representing the effect of catching up. The second term between brackets reflects the technological change or the effect of the shift in the technology frontier, as represented by $\left[\frac{\rho_{k}^{t}\left(x^{t}, y^{t}, b^{t}\right)}{\rho_{k}^{t+1}\left(x^{t}, y^{t}, b^{t}\right)} \times \frac{\rho_{k}^{t}\left(x^{t+1}, y^{t+1}, b^{t+1}\right)}{\rho_{k}^{t+1}\left(x^{t+1}, y^{t+1}, b^{t+1}\right)}\right]^{1 / 2}$. Moreover, $E C_{k}^{t, t+1}>1(<1)$ indicates an improvement (degradation) of relative efficiency during the period from $t$ to $t+1$, while a value of $T C_{k}^{t, t+1}$ greater (less) than one indicates progress (deterioration) of technology between periods $t$ and $t+1$. 


\subsection{The Measure and Direction of the Biased Technological Change}

Based on the decomposition above, following Färe et al. [53], TC can be initially decomposed into a magnitude index (the magnitude of technological change, MTC) and a technical bias index (the bias of technological change, BTC). The latter is further decomposed into an input bias index (the input-biased technological change, IBTC) and an output bias index (the output-biased technological change, OBTC), taking the forms as follows.

$$
\begin{gathered}
\operatorname{TC}_{k}^{t, t+1}=\left[\frac{\rho_{k}^{t}\left(x^{t}, y^{t}, b^{t}\right)}{\rho_{k}^{t+1}\left(x^{t}, y^{t}, b^{t}\right)} \times \frac{\rho_{k}^{t}\left(x^{t+1}, y^{t+1}, b^{t+1}\right)}{\rho_{k}^{t+1}\left(x^{t}, y^{t}, b^{t}\right)}\right]^{1 / 2} \\
=\frac{\rho_{k}^{t}\left(x^{t+1}, y^{t+1}, b^{t+1}\right)}{\rho_{k}^{t+1}\left(x^{t+1}, y^{t+1}, b^{t+1}\right)} \times\left[\frac{\rho_{k}^{t}\left(x^{t}, y^{t}, b^{t}\right)}{\rho_{k}^{t+1}\left(x^{t}, y^{t}, b^{t}\right)} \times \frac{\rho_{k}^{t+1}\left(x^{t+1}, y^{t+1}, b^{t+1}\right)}{\rho_{k}^{t}\left(x^{t+1}, y^{t+1}, b^{t+1}\right)}\right]^{1 / 2} \\
=\operatorname{MTC}_{k}^{t, t+1} \times B T C_{k}^{t, t+1}
\end{gathered}
$$

and

$$
\begin{gathered}
B T C_{k}^{t, t+1}=\left[\frac{\rho_{k}^{t}\left(x^{t}, y^{t}, b^{t}\right)}{\rho_{k}^{t+1}\left(x^{t}, y^{t}, b^{t}\right)} \times \frac{\rho_{k}^{t+1}\left(x^{t+1}, y^{t+1}, b^{t+1}\right)}{\rho_{k}^{t}\left(x^{t+1}, y^{t+1}, b^{t+1}\right)}\right]^{1 / 2} \\
=\left[\frac{\rho_{k}^{t+1}\left(x^{t}, y^{t}, b^{t}\right)}{\rho_{k}^{t}\left(x^{t}, y^{t}, b^{t}\right)} \times \frac{\rho_{k}^{t}\left(x^{t+1}, y^{t}, b^{t}\right)}{\rho_{k}^{t+1}\left(x^{t+1}, y^{t}, b^{t}\right)}\right]_{k}^{1 / 2} \times\left[\frac{\rho_{k}^{t}\left(x^{t+1}, y^{t+1}, b^{t+1}\right)}{\rho_{k}^{t+1}\left(x^{t+1}, y^{t+1}, b^{t+1}\right)} \times \frac{\rho_{k}^{t+1}\left(x^{t+1}, y^{t}, b^{t}\right)}{\rho_{k}^{t}\left(x^{t+1}, y^{t}, b^{t}\right)}\right]^{1 / 2} \\
=I B T C_{k}^{t, t+1} \times O B T C_{k}^{t, t+1}
\end{gathered}
$$

where $T C_{k}^{t, t+1}=M T C_{k}^{t, t+1} \times I B T C_{k}^{t, t+1} \times O B T C_{k}^{t, t+1} . \quad \rho_{k}^{t}\left(x^{t+1}, y^{t}, b^{t}\right)$ and $\rho_{k}^{t+1}\left(x^{t+1}, y^{t}, b^{t}\right)$ are the efficiency values based on period $t+1$ inputs, period $t$ desirable and undesirable outputs for the production technology at period $t$ and $t+1$, respectively. MTC indicates the Hicks-neutral technological change, as represented by the ratio in Equation (5), referring to the "homothetic" or "neutral" shift of the technology frontier. The second term of Equation (5) denotes the bias of technological change, indicating the effect of the "non-homothetic" or "non-neutral" shift in the technology frontier. Moreover, the two geometric means shown in Equation (6) denote the IBTC and the OBTC, respectively, reflecting the effect of change of the MRS of inputs and outputs caused by the technological change. If IBTC (OBTC) is greater (less) than 1, there exists progress (deterioration) in input-biased (output-biased) technology. When the IBTC and OBTC are equal to 1, then the technological change is Hicks-neutral.

It must be noted that the input-/output-biased technological change index cannot reflect the direction of the bias of technological change, such as being in favor of using labor relative to capital. Following Fare et al. [59], if the ratio between Input $1\left(x_{1}\right)$ and Input $2\left(x_{2}\right)$ increases from period $t$ to period $t+1\left(x_{2}^{t+1} / x_{1}^{t+1}>x_{2}^{t} / x_{1}^{t}\right)$, IBTC $>1$ indicates an $x_{2}$-using $/ x_{1}$-saving technological bias and IBTC $<1$ indicates an $x_{1}$-using/ $x_{2}$-saving technological bias. When $x_{2}^{t+1} / x_{1}^{t+1}<x_{2}^{t} / x_{1}^{t}$, IBTC $>1$ indicates an $x_{1}$-using $/ x_{2}$-saving technological bias and IBTC $<1$ indicates an $x_{2}$-using $/ x_{1}$-saving technological bias. Furthermore, the input-biased technological change is Hicks-neutral when IBTC $=1$. The $x_{2}$-using $/ x_{1}$-saving technological bias implies that the input-biased technology is biased in favor of using more Input 2 relative to Input 1 , while the $x_{1}$-using $/ x_{2}$-saving technological bias implies that the input-biased technology tends to use more Input 1 rather than Input 2.

Similarly to the input-biased technological change, when OBTC $>1$, an increase in the marginal rate of transformation (MRT) between Output $1\left(y_{1}\right)$ and Output $2\left(y_{2}\right)\left(y_{2}^{t+1} / y_{1}^{t+1}>y_{2}^{t} / y_{1}^{t}\right)$ indicates a $y_{2}$-producing technological bias, while a decrease in the MRT between the two outputs $\left(y_{2}^{t+1} / y_{1}^{t+1}<y_{2}^{t} / y_{1}^{t}\right)$ indicates a $y_{1}$-producing technological bias. If OBTC $<1, y_{2}^{t+1} / y_{1}^{t+1}>y_{2}^{t} / y_{1}^{t}$ indicates a $y_{1}$-producing technological bias and $y_{2}^{t+1} / y_{1}^{t+1}<y_{2}^{t} / y_{1}^{t}$ indicates a $y_{2}$-producing technological bias. The technological change concerning output is Hicks-neutral when OBTC $=1$. The $y_{1}$-producing technological bias implies that output-biased technology tends to produce more $y_{1}$ relative to $y_{2}$, while $y_{2}$-producing technological bias is biased in favor of producing more $y_{2}$ relative to $y_{1}$. 


\subsection{Data and Sources}

In the DEA-related literature, the choice of input and output indicators is important, and can directly influence the accuracy of the results. Based on previous studies, in this paper, three inputs and two outputs were adopted to evaluate the green TFP, bias of technological change, input-biased technological change, and output-biased technological change. Capital, labor, and energy were the input measures, while the value added of China's regional transportation was the desirable output and $\mathrm{CO}_{2}$ emissions was the undesirable output.

Labor: The total number of regional transportation employees was used to reflect the labor element of the sector.

Capital: Owing to the lack of official capital stock statistics in China's regional transportation sector, a number of previous studies used fixed capital investment to measure capital [41,42], while the majority of studies estimated capital stock via the perpetual inventory method (PIM) $[60,61]$. In this study, we used the popular capital measure of capital stock, which is calculated as follows.

$$
K_{t}=\left(1-d_{t}\right) K_{t-1}+I_{t}
$$

where $K_{t}$ and $K_{t-1}$ are the capital stock of period $t$ and period $t-1$, respectively, $I_{t}$ is the fixed asset investment in period $t$, and $d_{t}$ denotes the depreciation rate in period $t$ (based on Wang and He [60]). Here, the fixed asset investment and capital stock were both measured at 2004 constant prices.

Energy: The total energy consumption of all types of fuels (coal, gasoline, diesel, kerosene, natural gas, and electricity) reflects the energy material elements. These figures were converted into the unit of $10^{4}$ tons of standard coal equivalent.

Desirable output: Several measures of desirable outputs have been used in previous studies, including turnover volume [62] and value added of regional transportation [41-43]. Given that airline turnover volume figures are not reported for some provinces, we used the value added of each provincial transportation as the desirable output, which was also measured at 2004 constant prices.

Undesirable output: Carbon dioxide emission is adopted as the undesirable output. Because of the lack of official statistics of this figure, the approach of the fuel-based carbon calculation model developed by the Intergovernmental Panel on Climate Change 2006 (IPCC, 2006) was used to estimate the $\mathrm{CO}_{2}$ emissions of the regional transportation sector.

To identify the influencing factors of technological bias, several variables, including average years of education per employee, the number of green patents in transportation, energy price, transportation industrial scale, local government transportation fiscal expenditure, transportation structure, and R\&D investment in transportation, were adopted in this paper.

The average years of education per employee: Due to the lack of official statistics for the degree of education for transportation employees, we used the average years of education per person in the region as a surrogate variable, evaluated following Li et al. [35].

The number of green patents in transportation: This variable represents actual green innovation, which is the summary of green patent applications for the transportation industry in each province according to the International Patent Classification (IPC) Green Inventory.

Energy price: The energy price is the price index of the vehicle fuel costs in each province and was measured at 2004 constant prices.

Transportation industrial scale: This index is used to reflect the scale of transportation, and was estimated by the ratio of value added of regional transportation to that of each province.

Local government transportation fiscal expenditure: To reflect the degree of government attention paid to transportation, we used the index of the ratio of transportation fiscal expenditure to total regional fiscal expenditure. In China, the impact of local government on the industrial economy is significant, and may promote the bias of technological progress by providing more car-charging sites and subsidizing operators to purchase green cars instead of high-emissions vehicles, as well as by formulating development goals of energy conservation and emission reduction for industry. 
Transportation structure: Transportation structure is the ratio of the total converted turnover volume of rail and water transportation to the whole converted turnover volume (rail, water, and road). Different transportation types have different demands on the inputs (capital, labor, and material) and have different production technologies, which thus can affect the bias of technological change with the change of transportation structure.

$R \& D$ investment in transportation: This index indicates the research input, which is an important influence on the production of innovation or technology progress. Official statistics of the R\&D investment in regional transportation are lacking, so we adopted R\&D investment per person of each region as a surrogate index.

The different energy consumption data of the regional transportation industry were collected from the China Energy Statistical Yearbook, while the green patents in transportation were collected from the National Intellectual Property Administration. All other data were drawn from the China Statistical Yearbook. The descriptive statistics of the various indicators used are reported in Table 1.

\section{Empirical Results and Discussion}

\subsection{The Green TFP Growth and Technological Bias}

To provide a greater understanding of green TFP growth and the bias of technological change, Table 2 reveals the geometric mean of green MPI and its decomposition in China's provinces during the period of 2006-2017. From the average results over the sample period, we noted that the green MPI showed a downtrend, with a growth rate of $-5.3 \%$. Wang and He [60] and Li et al. [8] reported similar results during the periods of 2007-2012 and 2000-2010, respectively. The green MPIs of the provinces were almost all less than 1 (except for Zhejiang and Guizhou), indicating that a majority of DMUs performed worse between 2006 and 2017. From the decomposition, it was found that technological change was the major source of the degeneration of green TFP compared to efficiency change, with a contribution of $89.90 \%$ to total green productivity degeneration.

Figure 1 shows the green productivity change and its decomposition from 2006 to 2017, and Figure 2 displays the cumulative green productivity change and its decomposition. It can be easily seen that the green productivity of China's transportation industry decreased in most years. In addition, the trend of TC was generally similar to that of green MPI and was often less than 1, indicating that technological deterioration is often the major reason for the degeneration of green total productivity. Moreover, the decomposition of TC highlighted that the changes of green TFP were caused predominantly by the magnitude of technological change according to the similar tendency of MTC and MPI, as displayed in Figure 1b, implying that China's transportation industry does not achieve economy of scale. This is consistent with the fact that the enterprises are often small and numerous in this sector, particularly for road freight transportation. Another important reason is the quantity- and supply-oriented economic development pattern, which has caused a serious oversupply problem in the transportation industry [49]. 
Table 1. The descriptive statistics of the input and output indicators for the transportation industry of 30 provinces in China during $2005-2017$.

\begin{tabular}{|c|c|c|c|c|c|c|c|}
\hline & Variable & Description of Variable & Unit & Min & $\operatorname{Max}$ & Average & S. D \\
\hline \multirow{5}{*}{ Inputs and Outputs } & $\mathrm{L}$ & Labor & Ten thousand person & 2.807 & 85.400 & 23.892 & 14.686 \\
\hline & K & Capital stock & 100 million yuan & 64.190 & $16,279.742$ & 3198.319 & 2921.265 \\
\hline & $\mathrm{E}$ & Energy consumption & Ten thousand tons & 37.201 & 3314.667 & 905.319 & 601.212 \\
\hline & trans_added & Value added & 100 million yuan & 31.421 & 2968.661 & 667.970 & 521.530 \\
\hline & $\mathrm{CO}_{2}$ & Carbon dioxide emission & Ten thousand tons & 79.184 & 6783.796 & 1868.001 & 1252.253 \\
\hline \multirow{7}{*}{ Influencing Factors } & lnedu & \multicolumn{2}{|c|}{ Natural log of average years of education per person } & 0.819 & 1.097 & 0.944 & 0.046 \\
\hline & lnpatent & \multicolumn{2}{|c|}{ Natural log of number of green patents } & -1.000 & 3.383 & 1.855 & 0.812 \\
\hline & lnprice & \multicolumn{2}{|c|}{ Natural log of energy policy } & 2.040 & 2.244 & 2.129 & 0.050 \\
\hline & lnscale & \multicolumn{2}{|c|}{ Natural log of industrial scale } & -1.700 & -0.940 & -1.277 & 0.137 \\
\hline & lnexpend & \multicolumn{2}{|c|}{ Nature log of local government fiscal expenditure } & -0.334 & 1.207 & 0.706 & 0.241 \\
\hline & lntrans_str & \multicolumn{2}{|c|}{ Natural log of transportation structure } & -0.535 & -0.003 & -0.208 & 0.134 \\
\hline & $\ln r d$ & \multicolumn{2}{|c|}{ Natural log of R\&D investment per person } & 0.435 & 3.175 & 1.532 & 0.538 \\
\hline
\end{tabular}


Table 2. The geometric means of green total factor productivity and its decomposition from 2006 to 2017.

\begin{tabular}{|c|c|c|c|c|c|c|c|c|c|c|c|c|c|c|}
\hline \multirow{2}{*}{ Regions } & \multicolumn{2}{|c|}{ MPI } & \multicolumn{2}{|c|}{ EC } & \multicolumn{2}{|c|}{ TC } & \multicolumn{2}{|c|}{ MTC } & \multicolumn{2}{|c|}{ BTC } & \multicolumn{2}{|c|}{ IBTC } & \multicolumn{2}{|c|}{ OBTC } \\
\hline & Value & S. D & Value & S. D & Value & S. D & Value & S. D & Value & S. D & Value & S. D & Value & S. D \\
\hline Beijing (BJ) & 0.920 & 0.149 & 1.015 & 0.115 & 0.907 & 0.099 & 0.880 & 0.140 & 1.030 & 0.097 & 1.032 & 0.098 & 0.998 & 0.009 \\
\hline Tianjin (TJ) & 0.945 & 0.139 & 1.001 & 0.112 & 0.943 & 0.111 & 0.896 & 0.159 & 1.053 & 0.092 & 1.052 & 0.092 & 1.001 & 0.001 \\
\hline Hebei (HeB) & 0.993 & 0.039 & 1.000 & 0.000 & 0.993 & 0.039 & 0.944 & 0.058 & 1.053 & 0.029 & 1.062 & 0.046 & 0.991 & 0.041 \\
\hline Shanxi (ShaX) & 0.887 & 0.223 & 1.000 & 0.243 & 0.887 & 0.110 & 0.860 & 0.150 & 1.031 & 0.088 & 1.052 & 0.098 & 0.980 & 0.044 \\
\hline Inner Mongolia (IM) & 0.988 & 0.106 & 1.004 & 0.135 & 0.984 & 0.067 & 0.979 & 0.067 & 1.005 & 0.009 & 1.006 & 0.007 & 0.999 & 0.002 \\
\hline Liaoning (LN) & 0.937 & 0.149 & 1.006 & 0.137 & 0.932 & 0.081 & 0.914 & 0.104 & 1.020 & 0.045 & 1.024 & 0.043 & 0.996 & 0.010 \\
\hline Jilin (JL) & 0.947 & 0.052 & 0.983 & 0.074 & 0.964 & 0.062 & 0.957 & 0.063 & 1.007 & 0.007 & 1.007 & 0.007 & 1.000 & 0.001 \\
\hline Heilongjiang (HLJ) & 0.903 & 0.135 & 0.975 & 0.097 & 0.926 & 0.106 & 0.898 & 0.150 & 1.031 & 0.104 & 1.032 & 0.104 & 1.000 & 0.001 \\
\hline Shanghai (SH) & 0.956 & 0.107 & 1.007 & 0.114 & 0.950 & 0.050 & 0.944 & 0.054 & 1.006 & 0.011 & 1.006 & 0.011 & 1.000 & 0.000 \\
\hline Jiangsu (JS) & 0.970 & 0.107 & 1.040 & 0.119 & 0.933 & 0.075 & 0.914 & 0.107 & 1.021 & 0.093 & 1.011 & 0.087 & 1.010 & 0.016 \\
\hline Zhejiang (ZJ) & 1.017 & 0.052 & 1.014 & 0.079 & 1.003 & 0.083 & 0.992 & 0.069 & 1.012 & 0.026 & 1.005 & 0.005 & 1.007 & 0.025 \\
\hline Anhui (AH) & 0.905 & 0.066 & 0.948 & 0.059 & 0.955 & 0.078 & 0.934 & 0.103 & 1.022 & 0.045 & 1.023 & 0.046 & 1.000 & 0.001 \\
\hline Fujian (FJ) & 0.969 & 0.067 & 0.968 & 0.105 & 1.001 & 0.074 & 0.965 & 0.092 & 1.037 & 0.085 & 1.019 & 0.037 & 1.018 & 0.044 \\
\hline Jiangxi (JX) & 0.967 & 0.089 & 0.988 & 0.089 & 0.979 & 0.062 & 0.974 & 0.061 & 1.005 & 0.006 & 1.005 & 0.006 & 1.000 & 0.000 \\
\hline Shandong (SD) & 0.850 & 0.167 & 0.962 & 0.145 & 0.884 & 0.108 & 0.879 & 0.127 & 1.006 & 0.125 & 1.013 & 0.103 & 0.993 & 0.073 \\
\hline Henan $(\mathrm{HeN})$ & 0.939 & 0.078 & 0.981 & 0.102 & 0.958 & 0.070 & 0.948 & 0.073 & 1.010 & 0.011 & 1.015 & 0.017 & 0.995 & 0.009 \\
\hline Hubei (HuB) & 0.976 & 0.080 & 1.023 & 0.089 & 0.954 & 0.061 & 0.946 & 0.065 & 1.009 & 0.009 & 1.008 & 0.009 & 1.000 & 0.001 \\
\hline Hunan (HuN) & 0.893 & 0.144 & 1.003 & 0.099 & 0.890 & 0.121 & 0.820 & 0.180 & 1.085 & 0.121 & 1.087 & 0.120 & 0.999 & 0.003 \\
\hline Guangdong (GD) & 0.958 & 0.077 & 1.021 & 0.083 & 0.938 & 0.066 & 0.923 & 0.075 & 1.017 & 0.023 & 1.020 & 0.024 & 0.997 & 0.007 \\
\hline Guangxi (GX) & 0.972 & 0.078 & 1.010 & 0.089 & 0.963 & 0.065 & 0.955 & 0.067 & 1.008 & 0.007 & 1.008 & 0.007 & 1.000 & 0.001 \\
\hline Hainan $(\mathrm{HaN})$ & 0.954 & 0.123 & 0.999 & 0.093 & 0.955 & 0.072 & 0.943 & 0.084 & 1.013 & 0.026 & 1.013 & 0.026 & 1.000 & 0.001 \\
\hline Chongqing (CQ) & 0.975 & 0.063 & 0.995 & 0.102 & 0.980 & 0.063 & 0.973 & 0.063 & 1.007 & 0.008 & 1.007 & 0.008 & 1.000 & 0.001 \\
\hline Sichuan (SC) & 0.951 & 0.108 & 0.977 & 0.117 & 0.973 & 0.069 & 0.965 & 0.072 & 1.009 & 0.008 & 1.009 & 0.008 & 1.000 & 0.001 \\
\hline Guizhou (GZ) & 1.009 & 0.086 & 1.026 & 0.090 & 0.984 & 0.068 & 0.976 & 0.068 & 1.008 & 0.006 & 1.008 & 0.006 & 1.001 & 0.001 \\
\hline Yunnan (YN) & 0.951 & 0.083 & 0.965 & 0.105 & 0.986 & 0.062 & 0.978 & 0.062 & 1.007 & 0.008 & 1.007 & 0.008 & 1.000 & 0.000 \\
\hline Shaanxi (ShaaX) & 0.962 & 0.049 & 0.995 & 0.082 & 0.967 & 0.063 & 0.960 & 0.065 & 1.007 & 0.009 & 1.008 & 0.009 & 1.000 & 0.001 \\
\hline Gansu (GS) & 0.910 & 0.119 & 0.953 & 0.104 & 0.954 & 0.057 & 0.948 & 0.059 & 1.006 & 0.007 & 1.006 & 0.007 & 1.000 & 0.000 \\
\hline Qinghai (QH) & 0.918 & 0.077 & 0.930 & 0.095 & 0.987 & 0.058 & 0.982 & 0.059 & 1.005 & 0.005 & 1.005 & 0.005 & 1.000 & 0.001 \\
\hline Ningxia (NX) & 0.935 & 0.157 & 1.029 & 0.152 & 0.909 & 0.114 & 0.883 & 0.143 & 1.029 & 0.050 & 1.034 & 0.054 & 0.995 & 0.018 \\
\hline Xinjiang (XJ) & 0.981 & 0.094 & 1.026 & 0.101 & 0.957 & 0.056 & 0.951 & 0.055 & 1.006 & 0.006 & 1.006 & 0.006 & 1.000 & 0.000 \\
\hline Average & 0.947 & 0.111 & 0.994 & 0.109 & 0.953 & 0.081 & 0.935 & 0.100 & 1.019 & 0.057 & 1.019 & 0.055 & 0.999 & 0.020 \\
\hline
\end{tabular}




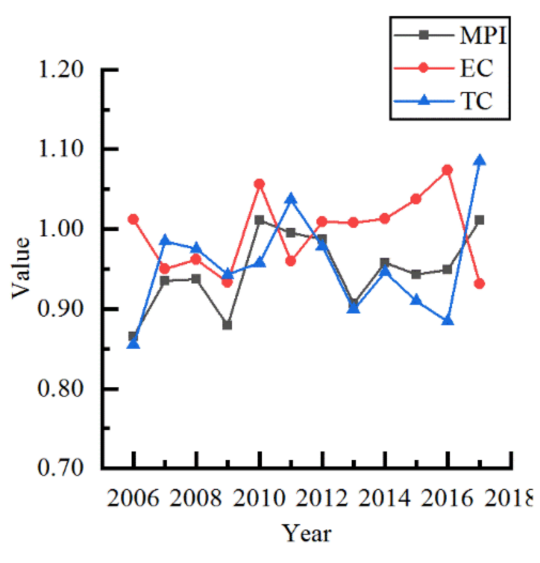

(a)

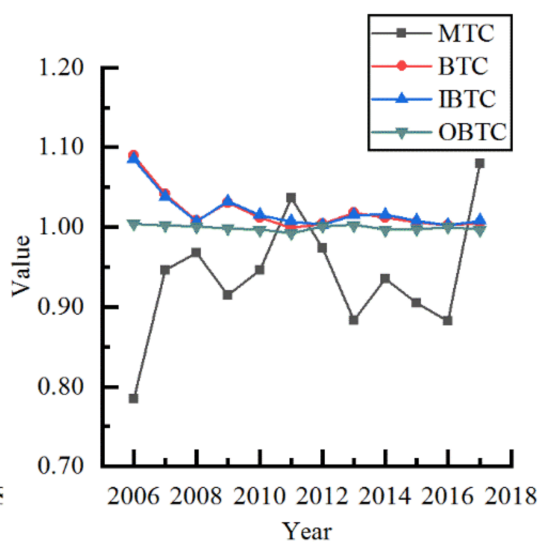

(b)

Figure 1. MPI and its decomposition: (a) MPI, efficiency change (EC) and technological change (TC), and (b) TC decomposition (magnitude of technological change (MTC), input-biased technological change (IBTC), and output-biased technological change (OBTC)).

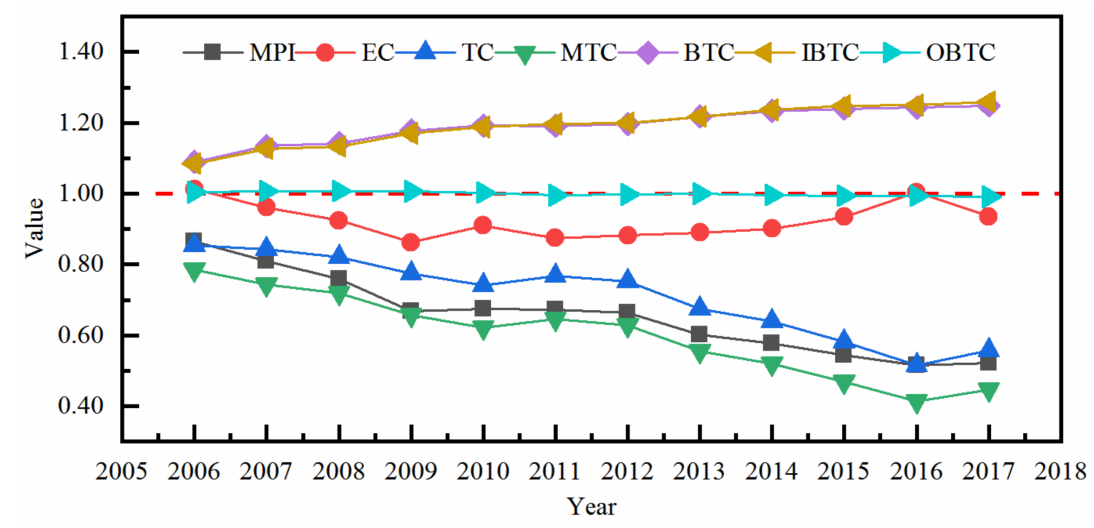

Figure 2. Cumulative green productivity change and its decomposition in China's transportation industry.

For technological bias, we note that, as shown in Table 2, the bias of technological change (1.019) was greater than 1, indicating that the technological bias of China's transportation industry experienced an average increase of $1.9 \%$ per year during the research period. This result also implies that technological bias had a significant positive influence on green productivity growth in China's transportation industry and suppressed the decrease in green TFP, with a moderate contribution of $-35.48 \%$. This relationship was also demonstrated by a negative Pearson correlation coefficient $(-0.369)$, which passed a significance level of $1 \%$. The decomposition of BTC showed that input-biased technology increased by $1.9 \%$ per year on average, while output-biased technology (0.999) experienced technological deterioration during the research period, indicating that the former was the major reason for the bias of technological progress. The Pearson correlation coefficient also showed that IBTC and MPI were highly negatively related, with a corresponding value of -0.397 and a $p$-value less than 0.01 . This implies that the input-biased technological progress optimized the resource allocation structure of input elements, enhanced the marginal output capacity, and then played an important positive role in the green productivity growth of China's transportation industry. Compared to IBTC, the value of the geometric mean of OBTC was close to 1, indicating that OBTC was small and made a slight contribution to the TC and green productivity change.

We also noted that the degree of input-biased technological change decreased during 2006 and 2008, while it often fluctuated in a range between 1 and 1.02 from 2009 to 2017, although the value was always greater than unity over the research period. A similar dynamic change between BTC and IBTC indicated that input-biased technological progress was always the major source of 
technological bias. Furthermore, the output-biased technological change decreased by 0.017 during the period of 2006-2010 and increased over 2011-2017, but the value of this index was always close to 1, implying that the technology of carbon emission reduction has not been researched effectively and applied in practice.

In addition, it was clear from the results reported in Table 2 that the technological changes of China's transportation industry differed greatly in different areas. To provide a better understanding of the differences between regions, we divided the 30 provinces in China into Eastern, Central, and Western groups. Figure 3 displays the dynamic changes of cumulative BTC, IBTC, and OBTC of these three groups. For each of these groups, the growth of technological bias was always greater than 0 , indicating that technological bias generally increased in 2006-2017. Moreover, the cumulative technological bias in the Eastern region was slightly greater than that in the Central region, which was significantly greater than that in the Western region, highlighting an obvious difference between regions. This was consistent with China's economic and social development, i.e., R\&D investment, human capital, and the environment of innovation of Eastern and Central regions were consistently more advanced than those of the Western region. The decomposition of BTC showed that the difference between the Eastern and Central groups was caused mainly by the great difference in output-biased technological change, while the difference between Eastern/Central and Western regions was caused mainly by the low level of input-biased technological change. As shown in Figure 3, with the exception of the Eastern region in 2016, the cumulative input-biased technology of the three groups always showed an improvement tendency during the research period, which implied that technological change often affected a "non-neutral" shift of the frontier technology and then promoted the improvement of green TFP. In contrast to the difference between regions in BTC, the cumulative input-biased technology of the Central region was often greater than that of the Eastern region, and was always obviously greater than that of the Western region, meaning that the Western region needs to enact policies to improve the allocation of input elements. In addition, we found that the output-biased technology in the Eastern region was always greater than that in Central and Western regions, with output-biased technology of the Western region being greater than that of the Central region. The reasons for this may be twofold. The first is that the Eastern region is rich in science and education resources, generating more low-carbon technology in transportation than other regions. The second is that the economic efficiency of the Eastern region is often greater than that of other regions, i.e., the marginal output capacity of elements in the Eastern region is stronger, causing the value added of transportation per $\mathrm{CO}_{2}$ emission in the Eastern region to be greater than that in others. For instance, in 2017, the value added of transportation per $\mathrm{CO}_{2}$ emission in the Eastern, Central, and Western regions was 0.482, 0.375 , and $0.28710,000$ tons $/ 100$ million Yuan, respectively.

Table 3 reports the number of provinces showing different types of technological bias split up by the degree of IBTC and OBTC during the periods of 2006-2008, 2009-2011, 2012-2014, and 2015-2017. For the sample dataset of IBTC $>1$ (OBTC $>1)$, we used the median of IBTC (OBTC) as the threshold with which to divide IBTC (OBTC) into two groups-a greater bias of technological progress and a lower bias of technological progress-while for those value of IBTC (OBTC) less than unity, we also divided the them into greater bias of technological deterioration and lower bias of technological deterioration groups for IBTC(OBTC) values compared to the median.

As shown in Table 3, the majority of provinces experienced bias of technological progress during the research period, with corresponding numbers of provinces of 30, 29, 29, and 25 during the periods 2006-2008, 2009-2011, 2012-2014, and 2015-2017, respectively. Moreover, we noted that the number of provinces showing technological bias progress decreased from 2015 to 2017, which was caused mainly by input-biased technological deterioration in some provinces. In addition, the conclusion that IBTC was the major reason for the BTC was also demonstrated by the strong correlation between the number of provinces that experienced technological progress and the number of provinces that showed input-biased technological progress. 


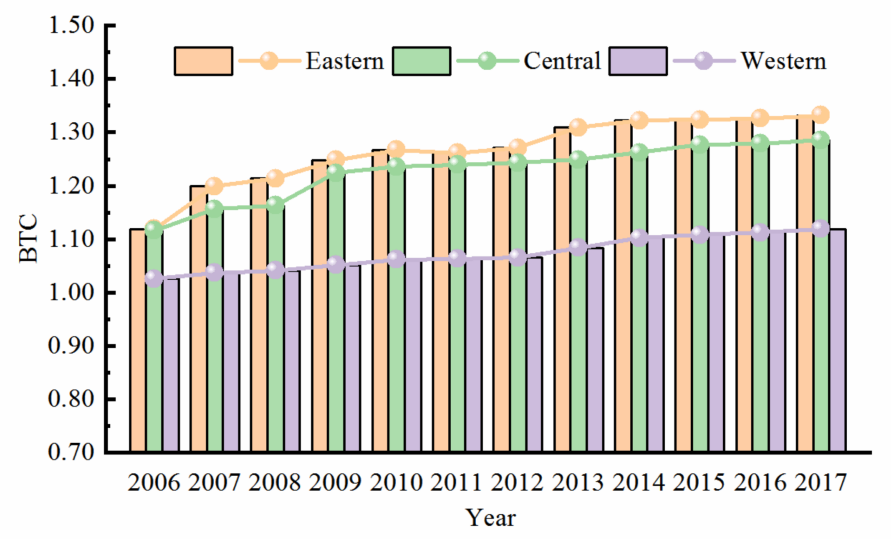

(a)

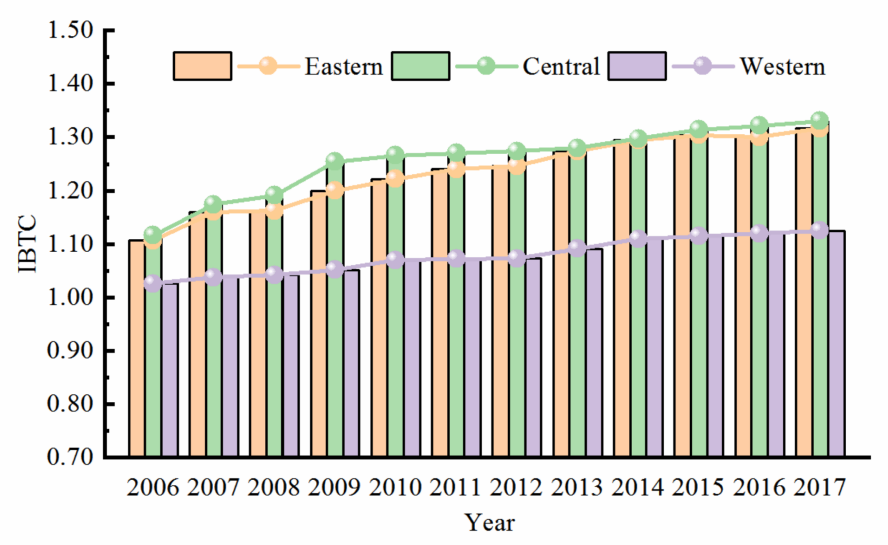

(b)

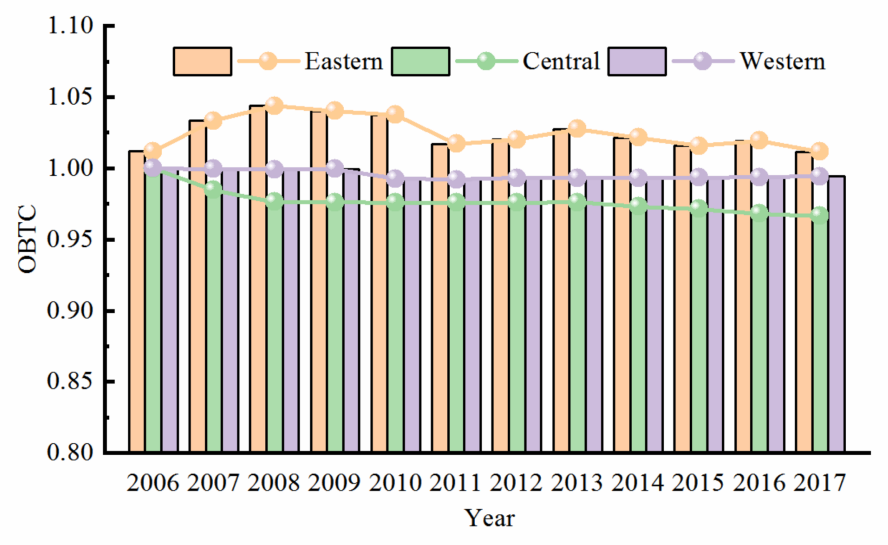

(c)

Figure 3. Cumulative technological bias in China's three regional transportation: (a) bias of technological change (BTC), (b) IBTC, and (c) OBTC. 
Table 3. The number of provinces showing different types of technological bias.

\begin{tabular}{|c|c|c|c|c|c|c|c|c|}
\hline \multirow{2}{*}{ Period } & \multirow{2}{*}{$\begin{array}{l}\text { Technological } \\
\text { Bias }\end{array}$} & \multirow{2}{*}{$\begin{array}{c}\text { Input-biased } \\
\text { Technological Bias }\end{array}$} & \multirow{2}{*}{$\begin{array}{c}\text { Degree of Technological } \\
\text { Bias Change }\end{array}$} & \multicolumn{2}{|c|}{ OBTC $<1$} & \multicolumn{2}{|c|}{ OBTC > 1} & \multirow{2}{*}{ Total } \\
\hline & & & & Greater Deterioration & Lower Deterioration & Lower Progress & Greater Progress & \\
\hline \multirow{4}{*}{ 2006-2008 } & \multirow{4}{*}{ BTC > 1 (30) } & \multirow{2}{*}{ IBTC > 1 (29) } & Lower progress & 1 & - & - & - & 1 \\
\hline & & & Greater progress & 8 & 6 & 6 & 8 & 28 \\
\hline & & IBTC $<1(1)$ & Lower deterioration & - & - & - & 1 & 1 \\
\hline & & Total & & 9 & 6 & 6 & 8 & - \\
\hline \multirow{4}{*}{ 2009-2011 } & \multirow{2}{*}{ BTC > 1 (29) } & \multirow{2}{*}{ IBTC > 1 (29) } & Lower progress & 1 & 7 & 7 & 2 & 17 \\
\hline & & & Greater progress & 4 & 4 & 3 & 1 & 12 \\
\hline & \multirow{2}{*}{ BTC < $1(1)$} & IBTC < $1(1)$ & Greater deterioration & 1 & - & - & - & 1 \\
\hline & & Total & & 6 & 11 & 10 & 3 & - \\
\hline \multirow{4}{*}{ 2012- 2014} & \multirow{4}{*}{ BTC > $1(30)$} & \multirow{2}{*}{ IBTC >1 (29) } & Lower progress & & 5 & 8 & 7 & 20 \\
\hline & & & Greater progress & 5 & 1 & 1 & 2 & 9 \\
\hline & & IBTC > $1(1)$ & Greater deterioration & - & - & - & 1 & 1 \\
\hline & & Total & & 5 & 6 & 9 & 10 & - \\
\hline \multirow{6}{*}{$2015-2017$} & \multirow{2}{*}{ BTC > 1 (25) } & \multirow{2}{*}{ IBTC > $1(25)$} & Lower progress & 1 & 5 & 6 & 5 & 17 \\
\hline & & & Greater progress & 5 & 1 & - & 2 & 8 \\
\hline & \multirow{4}{*}{ BTC $<1(5)$} & IBTC > 1 (3) & Lower progress & 3 & - & - & - & 3 \\
\hline & & \multirow{2}{*}{ IBTC $>1(2)$} & Greater deterioration & - & - & - & 1 & 1 \\
\hline & & & Lower deterioration & - & - & - & 1 & 1 \\
\hline & & Total & & 9 & 6 & 6 & 9 & - \\
\hline
\end{tabular}

Note: The table does not list the types of technological bias that were not experienced by any province; for instance, BTC $<1$ from 2006 to 2008 . The values in brackets represent the corresponding summary of the number of provinces. 
Similarly to BTC, the number of provinces that showed input-biased technological progress was 29 (2006-2008), 29 (2009-2011), 29 (2012-2014), and 25 (2015-2017), indicating that the input-biased technology of more than $80 \%$ of regions improved in 2006-2017. However, it was noted that the number of provinces that showed greater input-biased technological progress decreased during the sample period. In 2006-2008, 28 out of 30 provinces experienced greater input-biased technological progress, which decreased to 17, 20, and 17 in 2009-2011, 2012-2014, and 2015-2017, respectively. The reason for this may be the reduction of China's transportation infrastructure investment and the diminishing marginal effect of input-biased technological progress. Output-biased technological change was blended among provinces, with almost half of the provinces showing deterioration and the remainder showing progress, suggesting that the government still needs to promote the application of technology that improves production capacity and reduces carbon emissions. By combining IBTC and OBTC, it was also observed that different provinces showed different types of technological bias. With the exception of the period of 2006-2008, four major types of technological bias existed: (1) greater input-biased technological progress and greater output-biased technological deterioration; (2) lower input-biased technological progress and lower output-biased technological deterioration; (3) lower input-biased technological progress and lower output-biased technological progress; and (4) lower input-biased technological progress and greater output-biased technological progress.

To comprehensively identify the specific provinces that experienced different types of technological bias, we plotted the distribution of the provinces according to the geometric means of IBTC and OBTC during the research period using an approach similar to that described above. As displayed in Figure 4, Quadrant I indicates cases in which both IBTC and OBTC were greater than the medians of 1.0099 and 1.0002, respectively, representing greater input- and output-biased technological progress. The number of provinces of this type was small, and included Tianjin, Jiangsu, and Fujian. Quadrant II displays the cases where input-biased technological showed lower progress when the output-biased technological progress was greater, and these included Zhejiang, Hubei, and Guizhou. Quadrant III represents the cases when the input- and output-biased technological progress was greater and lower, respectively. The only province in this quadrant was Hainan. In Quadrant IV, the input- and output-biased technological change both showed lower progress, implying positive effects of both on green TFP. We note that this type of technological bias was one of the major types for China's transportation industry and included 6 out of 30 provinces (Jiangxi, Chongqing, Sichuan, Yunnan, Gansu, and Xinjiang). In Quadrant V, the input-biased technological change was greater than the value of the median and the output-biased technological change was less than 1 but greater than the median of OBTC $<1$, indicating that this quadrant represents the cases in which IBTC showed greater progress and OBTC showed lower deterioration. Like in the case of Quadrant III, the number of provinces in this quadrant was small; the provinces were limited to Heilongjiang and Anhui. We note that Quadrant VI contains relatively many provinces (6 out of 30) compared to other quadrants, which indicates that the input-and output-biased technology increased less and decreased less, respectively. The provinces included Inner Mongolia, Jilin, Shanghai, Guangxi, Shaanxi, and Qinghai. Quadrant VII represents the cases in which input- and output-biased technology showed greater progress and greater deterioration, respectively, and was also one of the major types for China's transportation industry; Quadrant VII included nine provinces, namely Beijing, Hebei, Shanxi, Liaoning, Shandong, Henan, Hunan, Guangdong, and Ningxia. 

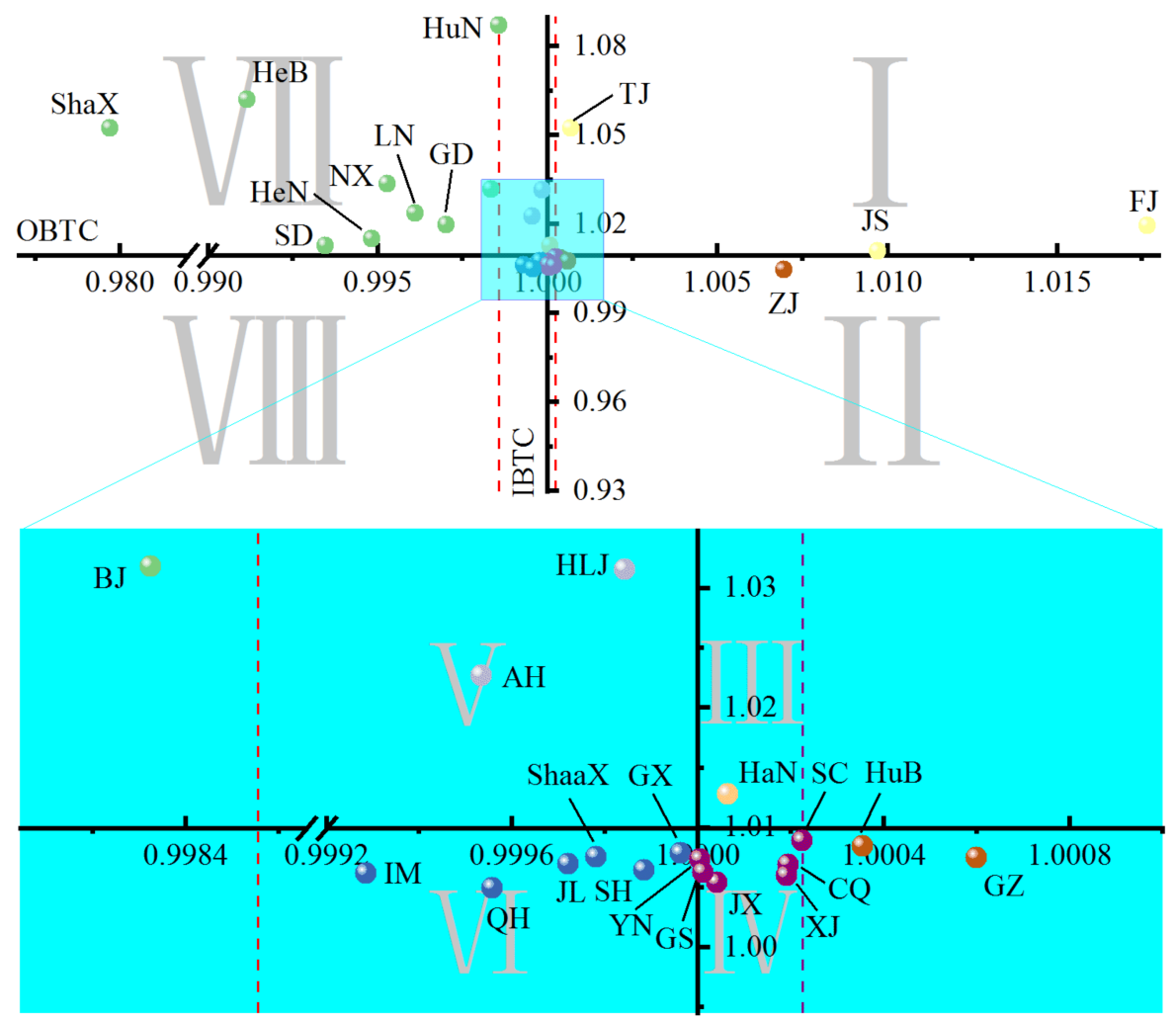

Figure 4. The distribution of the provinces in terms of different types of technological bias. Note: The red dotted lines indicate the median of OBTC less than 1 and the median of OBTC greater than 1 , respectively. The coordinate origin is (1, the median of IBTC), indicating that provinces located on the left (right) side of the vertical axis show output-biased technological degeneration (progress) and provinces located above (below) the horizontal axis show greater (lower) input-biased technological progress.

\subsection{The Direction of the Bias of Technological Change}

IBTC and OBTC cannot reflect the technological bias between special inputs and outputs, respectively. However, as noted in Section 3, the change of input and output mix can result in the special bias of technological change. Recall that there are three inputs, namely capital (K), labor (L), and energy (E), and two outputs, namely a desirable output (trans_added) and an undesirable output $\left(\mathrm{CO}_{2}\right)$. According to the approach mentioned above, we summarized the number of provinces that experienced technological bias for each year in Table 4 and reported the distribution of the direction of IBTC and OBTC for the overall research period in Tables 5 and 6. Comparisons between each pair of inputs or outputs were analyzed and some key observations were made.

According to Table 4, the majority of provinces experienced K-using/L-saving technological bias, with the exception of 2013. The comparison between $\mathrm{K}$ and $\mathrm{E}$ showed that the majority of provinces experienced K-using technological bias relative to $\mathrm{E}$ in each year. In addition, most provinces used $\mathrm{E}$ and saved L, with the exception of 2013. For the comparison between desirable output and undesirable output, 9 of 12 years showed a trans_added-producing bias compared to $\mathrm{CO}_{2}$.

As shown in Table 5, irrespective of the pairwise comparison, we noted that almost all of the provinces experienced input-biased technological progress during the sample period. For the comparison of $\mathrm{K}$ and $\mathrm{L}$, all of the provinces showed a bias in favor of using capital and saving labor, demonstrating K-using/L-saving technological bias progress. This result was similar to some findings reported for other regions or industries, such as those published by Chen and $\mathrm{Yu}$ [12] and Zha et al. [63]. With the widespread application of information and Internet technologies, in order to improve transportation efficiency, Chinese regional governments have also devoted resources to investing in such technologies in transportation management and organizations, thus leading to the 
improvement of labor productivity and the saving of labor. For instance, the application of the IC (integrated circuit) card has reduced the number of conductors in urban transportation. Furthermore, for the comparison of $\mathrm{K}$ and $\mathrm{E}$, all provinces experienced K-using/E-saving bias progress. Lin and Xie [31] also reported similar results. These findings indicate that China's transportation sector can reduce the growth rate of energy consumption and improve labor productivity by investing in more capital. In addition, for the comparison of $\mathrm{L}$ and $\mathrm{E}$, it was seen that the majority of the provinces (29 of 30) experienced a trend of utilizing more energy compared to labor, indicating that increased energy consumption could save some labor and increase labor productivity.

Table 4. Distributions of annual input-biased and output-biased technological changes.

\begin{tabular}{|c|c|c|c|c|c|c|c|c|}
\hline Period & \multicolumn{2}{|c|}{ K vs. L } & \multicolumn{2}{|c|}{ K vs. E } & \multicolumn{2}{|c|}{ L vs. E } & \multicolumn{2}{|c|}{ Trans_Added vs. $\mathrm{CO}_{2}$} \\
\hline 2006 & 30 & 0 & 30 & 0 & 0 & 30 & 29 & 1 \\
\hline 2008 & 28 & 2 & 29 & 1 & 8 & 22 & 30 & 0 \\
\hline 2009 & 29 & 1 & 29 & 1 & 10 & 20 & 29 & 1 \\
\hline 2010 & 29 & 1 & 29 & 1 & 3 & 27 & 1 & 29 \\
\hline 2012 & 26 & 4 & 25 & 5 & 8 & 22 & 28 & 2 \\
\hline 2013 & 16 & 14 & 27 & 3 & 25 & 5 & 29 & 1 \\
\hline 2014 & 25 & 5 & 29 & 1 & 10 & 20 & 24 & 6 \\
\hline 2015 & 28 & 2 & 28 & 2 & 9 & 21 & 19 & 11 \\
\hline 2016 & 24 & 6 & 20 & 10 & 7 & 23 & 4 & 26 \\
\hline 2017 & 30 & 0 & 28 & 2 & 8 & 22 & 21 & 9 \\
\hline
\end{tabular}

Note: The figures in Table 4 denote the number of provinces that experience the corresponding direction of technological bias.

Table 5. The direction of input-biased technological change and change of input mix in 2005-2017.

\begin{tabular}{ccccccc}
\hline \multicolumn{2}{c}{ K vs. L } & \multicolumn{2}{c}{ K vs. E } & \multicolumn{2}{c}{ L vs. E } \\
\hline & $\left(\frac{K}{L}\right)^{2017}>\left(\frac{K}{L}\right)^{2005}$ & $\left(\frac{K}{L}\right)^{2017}<\left(\frac{K}{L}\right)^{2005}$ & $\left(\frac{K}{E}\right)^{2017}>\left(\frac{K}{E}\right)^{2005}$ & $\left(\frac{K}{E}\right)^{2017}<\left(\frac{K}{E}\right)^{2005}$ & $\left(\frac{L}{E}\right)^{2017}>\left(\frac{L}{E}\right)^{2005}$ & $\left(\frac{L}{E}\right)^{2017}<\left(\frac{L}{E}\right)^{2005}$ \\
\hline IBT C $>1$ & 30 (K-using) & 0 (L-using) & 30 (K-using) & 0 (E-using) & 1 (L-using) & 29 (E-using) \\
IBTC $<1$ & 0 (L-using) & 0 (K-using) & 0 (E-using) & 0 (K-using) & 0 (E-using) & 0 (L-using) \\
IBTC $=1$ & 0 (Neutral) & 0 (Neutral) & 0 (Neutral) & 0 (Neutral) & 0 (Neutral) & 0 (Neutral) \\
\hline
\end{tabular}

Note: The figures in Table 5 denote the number of provinces that experience the corresponding direction of technological bias.

Table 6. The direction of output-biased technological change and change of output mix during 2005-2017.

\begin{tabular}{cccc}
\hline & OBTC $>\mathbf{1}$ & OBTC $<\mathbf{1}$ & OBTC $=\mathbf{1}$ \\
\hline$\left(\frac{\text { trans_added }}{\mathrm{CO}_{2}}\right)^{2017}>\left(\frac{\text { trans_added }}{\mathrm{CO}}\right)^{2005}$ & 19 (trans_added-producing) & $2\left(\mathrm{CO}_{2}\right.$-producing) & 0 (neutral) \\
$\left(\frac{\text { trans_added }}{\mathrm{CO}_{2}}\right)^{2017}<\left(\frac{\text { trans_added }}{\mathrm{CO}_{2}}\right)^{2005}$ & $2\left(\mathrm{CO}_{2}\right.$-producing) & 7 (trans_added-producing) & 0 (neutral) \\
\hline
\end{tabular}

Note: The figures in Table 6 denote the number of provinces that experience the corresponding direction of technological bias.

As shown in Table 6, the majority of provinces (21 of 30) experienced output-biased technological progress, while a smaller number of provinces (9 of 30) experienced deterioration of output-biased technological change. In addition, the majority of provinces (19 of 30) showed a bias in favor of producing desirable outputs (trans_added) relative to $\mathrm{CO}_{2}$ emissions. This effect was in large part due to a series of energy-saving and emission reduction policies that were continuously implemented after 2005. However, according to the analysis above, we found that the value of OBTC was close to 1, which implies that although those policies have played a positive role in promoting the reduction of $\mathrm{CO}_{2}$, the degree of the effect has been slight, suggesting that regional governments still need to strengthen the treatment of carbon emissions in transportation. Regarding values of OBTC $<1$, most provinces (seven of nine) exhibited a trend towards the use of technology that promotes trans_added relative to $\mathrm{CO}_{2}$ emissions; however, in reality, these regions often increased $\mathrm{CO}_{2}$ emissions rather than producing more 
desirable output (trans_added) in 2005-2017, resulting in a negative influence on green productivity growth. The lack of coordination of the direction of output-biased technological change and the output mix indicates that these regions should adjust the direction of output to improve green productivity. Moreover, the possible measures may be for governments to implement incentives to motivate regional transportation companies to more greatly reduce $\mathrm{CO}_{2}$ emissions.

\subsection{The Influencing Factors of Technological Bias}

The panel dataset measured above was used to investigate the influencing factors of technological bias for China's transportation industry. It should be noted that, given that cumulative bias of technological change (CBTC), cumulative input-biased technological change (CIBTC), and cumulative output-biased technological change (COBTC) can reflect the continuity of technological bias and can be compared among periods, we thus used CBTC, CIBTC, and COBTC in a regression analysis to investigate the influencing factors. The panel fixed effects (FE), random effects (RE), pooled ordinary least squares (OLS), and generalized least squares (GLS) approaches were the potential modeling options. However, using the likelihood ratio tests, we noted that there existed significant heteroskedasticity for each of CBTC, CIBTC, or COBTC, with corresponding test statistics of 733.330, 1024.150 , and 1716.300 , respectively, and $p$-values all less than 0.01 . Heteroskedasticity may lead to inaccurate results using the three former approaches, but can be avoided with the use of generalized least squares. Thus, this approach was adopted in this paper, and the results are reported in Table 7.

Table 7. Result of the generalized least squares regression model.

\begin{tabular}{cccc}
\hline & LnCBTC & LnCIBTC & LnCOBTC \\
\hline Lnedu & $0.596^{* * *}$ & $0.736^{* * *}$ & $-0.140^{* * *}$ \\
& $(3.989)$ & $(4.731)$ & $(-2.738)$ \\
Lnpatent & $0.028^{* * *}$ & $0.024^{* * *}$ & $0.004^{*}$ \\
& $(4.661)$ & $(3.845)$ & $(1.935)$ \\
Lnprice & -0.044 & -0.114 & $0.070^{* *}$ \\
& $(-0.438)$ & $(-1.094)$ & $(2.054)$ \\
Lnscale & $0.099 * * *$ & $0.152^{* * *}$ & $-0.053^{* * *}$ \\
& $(2.799)$ & $(4.123)$ & $(-4.370)$ \\
Lnexpend & $0.043^{* *}$ & $0.038^{*}$ & 0.004 \\
& $(2.091)$ & $(1.811)$ & $(0.607)$ \\
Lntrans_str & 0.043 & -0.040 & $0.083 * * *$ \\
& $(1.233)$ & $(-1.101)$ & $(6.979)$ \\
Lnrd & $-0.028^{* *}$ & $-0.025^{*}$ & -0.004 \\
& $(-2.280)$ & $(-1.905)$ & $(-0.873)$ \\
Constant & -0.296 & -0.223 & -0.073 \\
Log-Likelihood & $(-1.370)$ & $(-0.992)$ & $(-0.993)$ \\
Wald test & 427.926 & 413.644 & 815.352 \\
Obs & $97.710^{* * *}$ & $109.240 * * *$ & $73.740 * * *$ \\
\hline
\end{tabular}

Note: ${ }^{* * *}, * *$, and $*$ denote statistical significance at the $1 \%, 5 \%$, and $10 \%$ levels, respectively. The value in bracket is the corresponding t-test statistic.

Table 7 shows that, in addition to the transportation structure and energy prices, all variables had a significant effect on the technological bias, with corresponding $p$-values less than 0.05 . The following observations were also made: (1) We note that the impact of average years of education per person on the technological bias was positive, indicating that the technological bias will increase when the human capital of a region increases. (2) A positive correlation was found between the number of green patents and technological bias, but the correlation between R\&D investment and technological bias was negative. This was consistent with the finding that $R \& D$ investment has low efficiency in China's regions, as reported by many scholars [64]. Furthermore, this also implies that green patents in transportation have an important positive influence on the bias of technological progress. (3) We also 
found that the effects of industrial scale and transportation expenditure on the technological bias were positive, indicating that technological bias will increase if industrial scale increases and the local government pays more attention to this sector. In addition, from the regression results shown in the second column, it was seen that the influence of each variable on the input-biased technology progress was consistent with the overall technological bias, i.e., the average years of education per person, number of green patents in transportation, industrial scale, and transportation expenditure have a positive influence on the input-biased technology progress, while $R \& D$ investment has a negative effect. As stated by Li et al. [35], because the influences of IBTC and OBTC are contrasting, the directions of impact for each factor were opposing for IBTC and OBTC; this is shown in Table 7.

\section{Conclusions and Policy Implications}

By incorporating the slack-based measure and Malmquist productivity index, we examined the bias of technological change, input-biased technological change, and output-biased technological change, and their influencing factors in the sustainable development of China's provincial transportation industry from 2005 to 2017. We note that this paper has some limitations. For example, we did not investigate the technological bias in different transportation modes (e.g., road, water, railway, and air). As noted, different transportation modes use different production technologies, resulting in different input- and output-biased technologies. However, data for some variables are difficult to collect for specific transportation modes, such as carbon emissions for water transport. By focusing on the overall transportation industry, this paper provides significant value and meaning as a powerful reference for adjusting policies that improve the development of sustainable development in China's transportation industry. The conclusions and implications are as follows.

(1) During the study period, green productivity in transportation showed a continuous deterioration, with an annual growth rate of $-5.3 \%$ on average, indicating that there is substantial room for improvement. At the same time, the technological bias of China's transportation industry increased by $1.9 \%$ per year, and was the major positive driver of green TFP. Specifically, the input-biased technology experienced an increase of $1.9 \%$ per year, indicating that the positive effect of BTC was derived mainly from input-biased technological progress rather than the output-biased technological change. We also note that the degree of input-biased technological progress decreased over the research period, and the output-biased technological change was often close to 1 .

(2) Regarding technological bias, there were obvious differences in different regions. For the three major regions, the overall technological bias in the Eastern region was greater than that of the Central region, which, in turn, was greater than that of the Western region. However, the IBTC of the Central region was greater than that of the Eastern and Western regions. Moreover, the output-biased technology of the Eastern region exhibited the best performance among the three major regions, while the Central region's performance was the worst. In addition, according to the degree of IBTC and OBTC, we found that different provinces showed different types of technological bias, which were categorized into three main types during the overall period, including the cases of lower input-biased technological progress and lower output-biased technological deterioration, lower input-biased and output-biased technological progress, and greater input-biased technological progress and greater output-biased technological deterioration.

(3) The majority of provinces tended to show K-using/L-saving, K-using/E-saving, and E-using/ L-saving technological bias and trans_added-producing/ $\mathrm{CO}_{2}$-reducing technological bias. The analysis of influencing factors revealed that the average years of education per person, the number of green patents in transportation, industrial scale, and transportation expenditure contributed to promoting the improvement of the bias of technology, while R\&D investment had a negative effect.

Based on those conclusions, this paper provides policy implications or guidance for policy-makers as follows. Firstly, to develop sustainable development of regional transportation, the government 
should pay more attention to the differences between regions and formulate relevant policies according to local conditions that is, provinces should attract and strengthen resource elements that are compatible with local technology and promote the research and development of disadvantaged technologies. Secondly, the government still needs to vigorously promote and develop energy-saving and emission-reducing technology. Thirdly, policies, such as enhancing the cultivation of high-tech people; increasing subsidies for high-tech talents; encouraging technical learning; strengthening the in-depth integration of production, education, and research; improving R\&D performance; strengthening the management of local government; and promoting the reorganization and merger of transportation enterprises, should be implemented in China's transportation sector.

Author Contributions: Conceptualization, S.Z.; methodology, S.Z.; software, S.Z.; validation, C.Y. and X.W.; formal analysis, X.Z.; investigation, X.Z.; writing-original draft preparation, S.Z. and X.Z.; writing-review and editing, C.Y. and X.W.; visualization, X.Z.; supervision, C.Y. All authors have read and agreed to the published version of the manuscript.

Funding: This research received no external funding.

Acknowledgments: The authors are grateful to the editor and the anonymous reviewers of this paper.

Conflicts of Interest: The authors declare no conflict of interest.

\section{References}

1. Capuano, L. International Energy Outlook 2018 (IEO2018); US Energy Information Administration (EIA): Washington, DC, USA, 2018.

2. Lin, B.; Ahmad, I. Energy substitution effect on transport sector of Pakistan based on trans-log production function. Renew. Sustain. Energy Rev. 2016, 56, 1182-1193. [CrossRef]

3. Xu, B.; Luo, L.; Lin, B. A dynamic analysis of air pollution emissions in China: Evidence from nonparametric additive regression models. Ecol. Indic. 2016, 63, 346-358. [CrossRef]

4. IEA. $\mathrm{CO}_{2}$ Emissions from Fuel Combustion Highlights; International Energy Agency: Paris, France, 2012.

5. IEA. Transport, Energy and $\mathrm{CO}_{2}$ : Moving toward Sustainability; International Energy Agency: Paris, France, 2009.

6. China Energy Research Association. China Energy Development Report; China Energy Research Association: Zhejiang, China, 2016. (In Chinese)

7. Wang, $\mathrm{H}$.; $\mathrm{Ou}, \mathrm{X}$.; Zhang, X. Mode, technology, energy consumption, and resulting $\mathrm{CO}_{2}$ emissions in China's transport sector up to 2050. Energy Policy 2017, 109, 719-733. [CrossRef]

8. Li, Z.; Meng, N.; Yao, X. Sustainability performance for China's transportation industry under the environmental regulation. J. Clean. Prod. 2017, 142, 688-696. [CrossRef]

9. Han, R.; Yu, B.Y.; Tang, B.J.; Liao, H.; Wei, Y.M. Carbon emissions quotas in the Chinese road transport sector: A carbon trading perspective. Energy Policy 2017, 106, 298-309. [CrossRef]

10. Dong, J.; Deng, C.; Li, R.; Huang, J. Moving low-carbon transportation in Xinjiang: Evidence from STIRPAT and rigid regression models. Sustainability 2016, 9, 24. [CrossRef]

11. Bai, C.; Zhou, L.; Xia, M.; Feng, C. Analysis of the spatial association network structure of China's transportation carbon emissions and its driving factors. J. Environ. Manag. 2020, 253, 109765. [CrossRef]

12. Chen, P.C.; Yu, M.M. Total factor productivity growth and directions of technical change bias: Evidence from 99 OECD and non-OECD countries. Ann. Oper. Res. 2014, 214, 143-165. [CrossRef]

13. Wang, Q.; Zhang, C.; Cai, W. Factor substitution and energy productivity fluctuation in China: A parametric decomposition analysis. Energy Policy 2017, 109, 181-190. [CrossRef]

14. Jia, P.; Li, K.; Shao, S. Choice of technological change for China's low-carbon development: Evidence from three urban agglomerations. J. Environ. Manag. 2018, 206, 1308-1319. [CrossRef]

15. Goswami, M.; De, A.; Habibi, M.K.K.; Daultani, Y. Examining freight performance of third-party logistics providers within the automotive industry in India: An environmental sustainability perspective. Int. J. Prod. Res. 2020. [CrossRef]

16. Rajak, S.; Parthiban, P.; Dhanalakshmi, R. Sustainable transportation systems performance evaluation using fuzzy logic. Ecol. Indic. 2016, 71, 503-513. [CrossRef]

17. Shiau, T.A.; Huang, M.W.; Lin, W.Y. Developing an indicator system for measuring Taiwan's transport sustainability. Int. J. Sustain. Transp. 2014, 9, 81-92. [CrossRef] 
18. Wei, J.; Xia, W.; Guo, X.; Marinova, D. Urban transportation in Chinese cities: An efficiency assessment. Transp. Res. Part D Transp. Environ. 2013, 23, 20-24. [CrossRef]

19. Zhang, N.; Zhou, P.; Kung, C.C. Total-factor carbon emission performance of the Chinese transportation industry: A bootstrapped non-radial Malmquist index analysis. Renew. Sustain. Energy Rev. 2015, 41, 584-593. [CrossRef]

20. Tang, B.J.; Li, X.Y.; Yu, B.; Wei, Y.M. Sustainable development pathway for intercity passenger transport: A case study of China. Appl. Energy 2019, 254, 113632. [CrossRef]

21. Dioha, M.O.; Kumar, A. Sustainable energy pathways for land transport in Nigeria. Util. Policy 2020, 64, 101034. [CrossRef]

22. De, A.; Wang, J.; Tiwari, M.K. Fuel bunker management strategies within sustainable container shipping operation considering disruption and recovery policies. IEEE Trans. Eng. Manag. 2020, 1-23. [CrossRef]

23. De, A.; Choudhary, A.; Turkay, M.; Tiwari, M.K. Bunkering policies for a fuel bunker management problem for liner shipping networks. Eur. J. Oper. Res. 2019. [CrossRef]

24. Onat, N.; Kucukvar, M.; Tatari, O. Towards life cycle sustainability assessment of alternative passenger vehicles. Sustainability 2014, 6, 9305-9342. [CrossRef]

25. Streimikiene, D.; Baležentis, T.; Baležentienè, L. Comparative assessment of road transport technologies. Renew. Sustain. Energy Rev. 2013, 20, 611-618. [CrossRef]

26. Tsita, K.G.; Pilavachi, P.A. Decarbonizing the Greek road transport sector using alternative technologies and fuels. Therm. Sci. Eng. Prog. 2017, 1, 15-24. [CrossRef]

27. Feng, C.; Sun, L.X.; Xia, Y.S. Clarifying the "gains" and "losses" of transport climate mitigation in China from technology and efficiency perspectives. J. Clean. Prod. 2020, 263, 121545. [CrossRef]

28. Huang, F.; Zhou, D.; Hu, J.L.; Wang, Q. Integrated airline productivity performance evaluation with $\mathrm{CO}_{2}$ emissions and flight delays. J. Air Transp. Manag. 2020, 84, 101770. [CrossRef]

29. Liu, H.; $\mathrm{Wu}, \mathrm{J} . ; \mathrm{Chu}, \mathrm{J}$. Environmental efficiency and technological progress of transportation industry-based on large scale data. Technol. Forecast. Soc. Chang. 2018, 144, 475-482. [CrossRef]

30. Lin, B.; Raza, M.Y. Energy substitution effect on transport sector of Pakistan: A trans-log production function approach. J. Clean. Prod. 2020, 251, 119606. [CrossRef]

31. Lin, B.; Xie, C. Energy substitution effect on transport industry of China-based on trans-log production function. Energy 2014, 67, 213-222. [CrossRef]

32. Zhu, S.; Xu, X.; Ren, X.; Sun, T.; Oxley, L.; Rae, A.; Ma, H. Modeling technological bias and factor input behavior in China's wheat production sector. Econ. Model. 2016, 53, 245-253. [CrossRef]

33. Dewitte, R.; Dumont, M.; Merlevede, B.; Rayp, G.; Verschelde, M. Firm-heterogeneous biased technological change: A nonparametric approach under endogeneity. Eur. J. Oper. Res. 2020, 283, 1172-1182. [CrossRef]

34. Yang, Z.; Shao, S.; Li, C.; Yang, L. Alleviating the misallocation of R\&D inputs in China's manufacturing sector: From the perspectives of factor-biased technological innovation and substitution elasticity. Technol. Forecast. Soc. Chang. 2020, 151, 119878.

35. Li, J.; See, K.F.; Chi, J. Water resources and water pollution emissions in China's industrial sector: A green-biased technological progress analysis. J. Clean. Prod. 2019, 229, 1412-1426. [CrossRef]

36. Reisi, M.; Aye, L.; Rajabifard, A.; Ngo, T. Transport sustainability index: Melbourne case study. Ecol. Indic. 2014, 43, 288-296. [CrossRef]

37. Persia, L.; Cipriani, E.; Sgarra, V.; Meta, E. Strategies and measures for sustainable urban transport systems. Transp. Res. Procedia 2016, 14, 955-964. [CrossRef]

38. Gruyter, D.C.; Currie, G.; Rose, G. Sustainability measures of urban public transport in cities: A world review and focus on the Asia/middle east region. Sustainability 2016, 9, 43. [CrossRef]

39. Zhou, G.; Chung, W.; Zhang, X. A study of carbon dioxide emissions performance of China's transport sector. Energy 2013, 50, 302-314. [CrossRef]

40. Liu, Z.; Qin, C.X.; Zhang, Y.J. The energy-environment efficiency of road and railway sectors in China: Evidence from the provincial level. Ecol. Indic. 2016, 69, 559-570. [CrossRef]

41. Bi, G.; Wang, P.; Yang, F.; Liang, L. Energy and environmental efficiency of China's transportation sector: A Multidirectional analysis approach. Math. Probl. Eng. 2014, 6, 1-12.

42. Chang, Y.T.; Zhang, N.; Danao, D.; Zhang, N. Environmental efficiency analysis of transportation system in China: A non-radial DEA approach. Energy Policy 2013, 58, 277-283. [CrossRef] 
43. Park, Y.S.; Lim, S.H.; Egilmez, G.; Szmerekovsky, J. Environmental efficiency assessment of U.S. transport sector: A slack-based data envelopment analysis approach. Transp. Res. Part D Transp. Environ. 2018, 61, 152-164. [CrossRef]

44. Song, M.; Zheng, W.; Wang, Z. Environmental efficiency and energy consumption of highway transportation systems in China. Int. J. Prod. Econ. 2016, 181, 441-449. [CrossRef]

45. Tian, N.; Tang, S.; Che, A.; Wu, P. Measuring regional transport sustainability using super-efficiency SBM-DEA with weighting preference. J. Clean. Prod. 2020, 242, 118474. [CrossRef]

46. Wu, J.; Zhu, Q.; Chu, J.; Liu, H.; Liang, L. Measuring energy and environmental efficiency of transportation systems in China based on a parallel DEA approach. Transp. Res. Part D Transp. Environ. 2015, 48, 460-472. [CrossRef]

47. Liu, H.; Zhang, Y.; Zhu, Q.; Chu, J. Environmental efficiency of land transportation in China: A parallel slack-based measure for regional and temporal analysis. J. Clean. Prod. 2017, 142, 867-876. [CrossRef]

48. Liu, X.; Zhou, D.; Zhou, P.; Wang, Q. Dynamic carbon emission performance of Chinese airlines: A global Malmquist index analysis. J. Air Transp. Manag. 2017, 65, 99-109. [CrossRef]

49. Yu, Y.; Choi, Y.; Wei, X.; Chen, Z. Did China's regional transport industry enjoy better carbon productivity under regulations? J. Clean. Prod. 2017, 165, 777-787. [CrossRef]

50. Lee, B.L.; Wilson, C.; Pasurka, C.A.; Fujii, H.; Managi, S. Sources of airline productivity from carbon emissions: An analysis of operational performance under good and bad outputs. J. Product. Anal. 2017, 47, 223-246. [CrossRef]

51. Seufert, J.H.; Arjomandi, A.; Dakpo, K.H. Evaluating airline operational performance: A LuenbergerHicks-Moorsteen productivity indicator. Transp. Res. Part E Logist. Transp. Rev. 2017, 104, 52-68. [CrossRef]

52. Mavi, R.K.; Fathi, A.; Saen, R.F.; Mavi, N.K. Eco-innovation in transportation industry: A double frontier common weights analysis with ideal point method for Malmquist productivity index. Resour. Conserv. Recycl. 2019, 147, 39-48. [CrossRef]

53. Fare, R.; Grifell-Tatje, E.; Grosskopf, S.; Knox Lovell, C.A. Biased technical change and the Malmquist productivity index. Scand. J. Econ. 1997, 99, 119-127. [CrossRef]

54. Agee, M.D.; Atkinson, S.E.; Crocker, T.D. Child maturation, time-invariant, and time-varying inputs: Their interaction in the production of child human capital. J. Product. Anal. 2012, 38, 29-44. [CrossRef]

55. Tone, K. Dealing with undesirable outputs in DEA: A slacks-based measure (SBM) approach. In Proceedings of the North American Productivity Workshop 2004, Toronto, ON, Canada, 23-25 June 2004; pp. 44-45.

56. Wang, W.; Chen, T. Efficiency evaluation and influencing factor analysis of China's public cultural services based on a Super-Efficiency Slacks-Based Measure model. Sustainability 2020, 12, 3146. [CrossRef]

57. Hosseini, K.; Stefaniec, A. Efficiency assessment of Iran's petroleum refining industry in the presence of unprofitable output: A dynamic two-stage slacks-based measure. Energy 2019, 189, 116112. [CrossRef]

58. Färe, R.; Grosskopf, S.; Lindgren, B.; Roos, P. Productivity changes in Swedish pharamacies 1980-1989: A non-parametric Malmquist approach. J. Product. Anal. 1992, 3, 85-101. [CrossRef]

59. Färe, R.; Grosskopf, S.; Lee, W.F. Productivity and technical change: The case of Taiwan. Appl. Econ. 2001, 33, 1911-1925. [CrossRef]

60. Wang, Z.; He, W. $\mathrm{CO}_{2}$ emissions efficiency and marginal abatement costs of the regional transportation sectors in China. Transp. Res. Part D Transp. Environ. 2017, 50, 83-97. [CrossRef]

61. Liu, W.; Lin, B. Analysis of energy efficiency and its influencing factors in China's transport sector. J. Clean. Prod. 2018, 170, 674-682. [CrossRef]

62. Cui, Q.; Li, Y. An empirical study on the influencing factors of transportation carbon efficiency: Evidences from fifteen countries. Appl. Energy 2015, 141, 209-217. [CrossRef]

63. Zha, D.; Kavuri, A.S.; Si, S. Energy biased technology change: Focused on Chinese energy-intensive industries. Appl. Energy 2017, 190, 1081-1089. [CrossRef]

64. Lin, X.P.; Niu, X.D. Study on the trend and influencing factors of China's regional directed technical change. Wuhan Univ. J. (Philos. Soc. Sci.) 2019, 72, 148-160. (In Chinese)

(C) 2020 by the authors. Licensee MDPI, Basel, Switzerland. This article is an open access article distributed under the terms and conditions of the Creative Commons Attribution (CC BY) license (http://creativecommons.org/licenses/by/4.0/). 